\title{
Structural variations in layered alkaline earth metal cyclohexyl phosphonates
}

\author{
RAMASWAMY MURUGAVEL* and NAYANMONI GOGOI \\ Department of Chemistry, Indian Institute of Technology Bombay, Powai Mumbai 400 076, India
}

\begin{abstract}
Two series of alkaline earth metal cyclohexyl phosphonates, $\mathrm{M}\left(\mathrm{C}_{6} \mathrm{H}_{11} \mathrm{PO}_{3} \mathrm{H}\right)_{2}\left(\mathrm{H}_{2} \mathrm{O}\right)(\mathrm{M}=\mathrm{Ca}, \mathrm{Sr}$ and $\mathrm{Ba})(1-3)$ and $\mathrm{M}\left(\mathrm{C}_{6} \mathrm{H}_{11} \mathrm{PO}_{3}\right)\left(\mathrm{H}_{2} \mathrm{O}\right)(\mathrm{M}=\mathrm{Mg}, \mathrm{Ca}$, Sr, and $\mathrm{Ba})(4-7)$ have been synthesized under mild reaction conditions. All new compounds have been characterized using elemental analysis, IR, TGA and powder $\mathrm{X}$-ray diffraction techniques. The molecular structure of compound 2 determined using single crystal X-ray diffraction technique reveals a layered polymeric structure.
\end{abstract}

Keywords. Metal phosphonates; layered compounds; X-ray structures.

\section{Introduction}

Metal organo-phosphonates offer a new class of layered structures where the organic groups are covalently attached to the inorganic backbone and consist of a sequence of alternating inorganic and organic layers. Owing to the unusual composition and layered structure, metal organo-phosphonates have found a wide range of applications as ion exchangers, radioactive waste disposal agents, stereoselective catalysts (Ungashe et al 1992), sensors and nonlinear optical materials (Wan et al 1994). Zirconium phosphonates were the first examples of this class of compounds which has structures closely related to their inorganic analogues and the chemical properties of these new compounds stimulated extensive exploitation (Alberti 1978; Cao et al 1992; Clearfield 1998). The mild preparative procedure of metal organophosphonates turned out to be the biggest advantage of this class of compounds over their completely inorganic counterparts. Unlike most inorganic layered solids, these compounds are generally synthesized at low temperature and often from an aqueous solution. The milder reaction conditions used for the synthesis of metal organo-phosphonates also made viable the incorporation of functional groups into the layers without disturbing the inorganic backbone. The most promising feature of these metal organophosphonates is the ease at which pillared or intercalated structures can be obtained (Lee et al 1988a, b). However, because of the entrance of the guest molecules between the layers, there will be a change in the interlayer distance (Alberti 1978). Although M(IV) organo-phosphonates are well documented, the chemistry of M(II) organophosphonates especially the alkaline earth metal

\footnotetext{
*Author for correspondence (rmv@chem.iitb.ac.in)
}

organophosphonates has been explored marginally (Cao et al 1998; Svoboda et al 2005). However, recent use of phosphonates based drugs for diagnosis and therapy of various diseases of bones and calcium metabolism made the chemistry of calcium phosphonates particularly appealing. This led to the synthesis and structural characterization of $\left.\left[\mathrm{M}_{(} \mathrm{C}_{6} \mathrm{H}_{5} \mathrm{PO}_{3} \mathrm{H}\right)_{2}\right] ;(\mathrm{M}=\mathrm{Ca}, \mathrm{Ba}$ and $\mathrm{Sr})$, and studies of intercalation of various alkyl amines into their layered structures. Another class of alkaline earth metal organo-phosphonates, $\left[\mathrm{M}\left(\mathrm{RPO}_{3}\right)\right]$, where the phosphonate ligands are in di-anionic form, are yet to be structurally characterized using single crystal X-ray diffraction studies.

Several routes including hydrothermal and softchemical methods have been used for the synthesis of metal organo-phosphonates. Nevertheless, the quest for structural characterization of the final product requires a preparation route, which provides crystalline material suitable for diffraction study. Therefore, choice of starting materials and reaction conditions are of great importance. Moreover, as the organic groups project themselves onto the interlayer space, the nature of organic groups has significant influence on the physical properties of the resultant metal organo-phosphonates. In the present study, we wish to investigate the alkaline earth metal phosphonates using cyclohexyl phosphonic acid. Although a number of alkyl and aryl phosphonates have been studied in considerable detail, the chemistry of cyclohexyl phosphonates which has the advantage of both alkyl and aryl phosphonic acids are investigated minimally. The synthesis and characterization of two homologous series of alkaline earth metal cyclohexyl phosphonates, viz. $\mathrm{M}\left(\mathrm{C}_{6} \mathrm{H}_{11} \mathrm{PO}_{3} \mathrm{H}\right)_{2}\left(\mathrm{H}_{2} \mathrm{O}\right)(\mathrm{M}=\mathrm{Ca}, \mathrm{Sr}$, and $\mathrm{Ba})(\mathbf{1}-\mathbf{3})$ and $\mathrm{M}\left(\mathrm{C}_{6} \mathrm{H}_{11} \mathrm{PO}_{3}\right)\left(\mathrm{H}_{2} \mathrm{O}\right)(\mathrm{M}=\mathrm{Mg}, \mathrm{Ca}, \mathrm{Sr}$, and $\mathrm{Ba})(4-7)$ has been reported in this paper. Also the molecular structure of $\operatorname{Sr}\left(\mathrm{C}_{6} \mathrm{H}_{11} \mathrm{PO}_{3} \mathrm{H}\right)_{2}\left(\mathrm{H}_{2} \mathrm{O}\right)$ has been determined using single crystal $\mathrm{X}$-ray diffraction technique. 


\section{Experimental}

\subsection{General}

All chemicals were procured from commercial sources and used as received. Solvents were purified and dried by conventional procedures and freshly distilled before use. Cyclohexyl phosphonic acid was prepared following a procedure reported earlier (Clayton and Jensen 1948). Infrared spectra were obtained on Perkin Elmer FT-IR spectrometer. Microanalyses were performed on a Thermo Finnigan (FLASH EA 1112) or a Carlo Erba 1106 microanalyzer. TG analyses were obtained from a Perkin Elmer thermal analyzer. Powder X-ray diffraction data were recorded on a PW3040/60 X'pert PRO console X-ray diffractometer. TEM images were obtained from a Fei Qunata 200 HV SEM with TSL-EDX OIM system.

\subsection{Synthesis of $\left[\mathrm{Ca}\left(\mathrm{C}_{6} \mathrm{H}_{11} \mathrm{PO}_{3} \mathrm{H}_{2}\left(\mathrm{H}_{2} \mathrm{O}\right)\right](\mathbf{1})\right.$}

A solution of $\mathrm{Ca}(\mathrm{OAc})_{2}(0.158 \mathrm{~g}, 1 \mathrm{mmol})$ in water $(15 \mathrm{~mL})$ was added under stirring to a solution of $\mathrm{C}_{6} \mathrm{H}_{11} \mathrm{PO}_{3} \mathrm{H}_{2}$ $(0.326 \mathrm{~g}, 2 \mathrm{mmol})$ in water $(20 \mathrm{~mL})$ at ambient temperature. Thin flake shaped white crystalline solid obtained immediately was filtered, washed several times with water and dried in a dessicator. Yield: $0.250 \mathrm{~g}(61 \%$ based on Ca); M.P. $>250^{\circ} \mathrm{C}$; elemental analysis, calcd (\%) for $\mathrm{C}_{12} \mathrm{H}_{26} \mathrm{CaO}_{7} \mathrm{P}_{2}$ : C 37.50, H 6.82; Found: C 35.45, $\mathrm{H}$ 6.84; IR (KBr, $\left.\mathrm{cm}^{-1}\right)$ : 3501(s), 3309(br), 2925(s), 2851(m), 2382(br), 1682(w), 1449(w), 1146(vs), 1038(s), 923(s), 577(w), 508(w).

\subsection{Synthesis of $\left[\mathrm{Sr}\left(\mathrm{C}_{6} \mathrm{H}_{11} \mathrm{PO}_{3} \mathrm{H}\right)_{2}\left(\mathrm{H}_{2} \mathrm{O}\right)\right]$ (2)}

To a solution of $\mathrm{C}_{6} \mathrm{H}_{11} \mathrm{PO}_{3} \mathrm{H}_{2}(0 \cdot 164 \mathrm{~g}, 1 \mathrm{mmol})$ in water $(15 \mathrm{~mL})$ was slowly added a suspension of $\mathrm{SrCO}_{3}(0 \cdot 147 \mathrm{~g}$, $1 \mathrm{mmol})$ in water $(20 \mathrm{~mL})$. While effervescence was observed, a clear solution was obtained after $2 \mathrm{~min}$. Colourless rectangular crystals were obtained after one week. Yield: $0.124 \mathrm{~g}(28 \%$ based on $\mathrm{Sr})$; M.P. $>250^{\circ} \mathrm{C}$; elemental analysis (anal. calc. for $\mathrm{C}_{12} \mathrm{H}_{26} \mathrm{SrO}_{7} \mathrm{P}_{2}$ ) $\mathrm{C}=33.37$, $\mathrm{H}=6.07$; found : $\mathrm{C}=32.27, \mathrm{H}=5.69 ; \mathrm{IR}\left(\mathrm{KBr}, \mathrm{cm}^{-1}\right)$ : 3499(m), 3324 (br), 2928(s), 2853 (m), 2294 (br), 1682 (br), 1457 (w), 1274 (w), $1138(\mathrm{~s}), 1019$ (m), 923 (s), 746 (w), $573(\mathrm{~m})$.

\subsection{Synthesis of $\left[\mathrm{Ba}\left(\mathrm{C}_{6} \mathrm{H}_{11} \mathrm{PO}_{3} \mathrm{H}_{2}\left(\mathrm{H}_{2} \mathrm{O}\right)\right]\right.$ (3)}

To a solution of $\mathrm{Ba}(\mathrm{OAc})_{2}(0.255 \mathrm{~g}, 1 \mathrm{mmol})$ in water $(15 \mathrm{~mL})$ was added a solution of $\mathrm{C}_{6} \mathrm{H}_{11} \mathrm{PO}_{3} \mathrm{H}_{2}(0.328 \mathrm{~g}$, $2 \mathrm{mmol})$ in water $(20 \mathrm{~mL})$ and the mixture was heated in a 1000 watt microwave oven for $2 \mathrm{~min}$. Following this, the solution was allowed to cool for $2 \mathrm{~min}$ and then again heated using the microwave oven for another $2 \mathrm{~min}$. This procedure was repeated once more and then clear solution obtained was kept at room temperature for crystallization. Colourless flake shaped crystals were formed after $6 \mathrm{~h}$, washed several times with water and then dried in a dessicator. Yield: $0.374 \mathrm{~g}(74 \%$ based on Ba); M.P.: $>260^{\circ} \mathrm{C}$; elemental analysis: (anal. calc. for $\mathrm{C}_{12} \mathrm{H}_{26} \mathrm{BaO}_{7} \mathrm{P}_{2}$ ) C 29.93, H 5.44; found: C 28.84, H 4.98; IR ( $\left.\mathrm{KBr}, \mathrm{cm}^{-1}\right)$ : 3423 (br), 2930 (s), 2852 (m), 2340 (br), 1451 (w), 1141 (s), $1066(\mathrm{~m}), 1031(\mathrm{~m}), 900$ (s), $878(\mathrm{w}), 572(\mathrm{w})$.

\subsection{Synthesis of $\left[\mathrm{Mg}\left(\mathrm{C}_{6} \mathrm{H}_{11} \mathrm{PO}_{3}\right)\left(\mathrm{H}_{2} \mathrm{O}\right)\right]$ (4)}

To an aqueous solution of $\mathrm{Mg}(\mathrm{OAc})_{2} \cdot 4 \mathrm{H}_{2} \mathrm{O}(0.214 \mathrm{~g}$, $1 \mathrm{mmol})$ was added a solution of $\mathrm{C}_{6} \mathrm{H}_{11} \mathrm{PO}_{3} \mathrm{H}_{2}(0 \cdot 164$, $1 \mathrm{mmol})$ in water $(10 \mathrm{~mL})$ and the clear solution obtained was heated in a water bath for $1 \mathrm{~h}$. The white crystalline solid obtained was filtered out and washed several times with water and then dried in a dessicator. Yield: $0.146 \mathrm{~g}$ (71\% based on $\mathrm{Mg}$ ); M.P. $>250^{\circ} \mathrm{C}$; elemental analysis: (anal. calcd. for $\mathrm{C}_{6} \mathrm{H}_{13} \mathrm{O}_{4} \mathrm{PMg}$ ) C $35 \cdot 24$, $\mathrm{H} \mathrm{6.40;} \mathrm{found:} \mathrm{C}$ 35.23, 6.38; IR ( $\left.\mathrm{KBr}, \mathrm{cm}^{-1}\right): 3480$ (br), 2929 (s), 2853 (m), 1615 (br), 1446 (w), 1278 (w), 1216 (w), 1091 (vs), 1017 (s), 988 (vs), 830 (w), 756 (w), 689 (m), 585 (w), $551(w)$.

\subsection{Synthesis of $\mathrm{Ca}\left(\mathrm{C}_{6} \mathrm{H}_{11} \mathrm{PO}_{3}\right)\left(\mathrm{H}_{2} \mathrm{O}\right)(\mathbf{5})$}

To an aqueous solution $(20 \mathrm{~mL})$ of $\mathrm{C}_{6} \mathrm{H}_{11} \mathrm{PO}_{3} \mathrm{H}_{2}(0 \cdot 164 \mathrm{~g}$, $1 \mathrm{mmol})$ was added $25 \%$ aqueous $\mathrm{NH}_{3}(0.3 \mathrm{~mL}, 4 \mathrm{mmol})$ solution and the whole was heated on a water-bath for $5 \mathrm{~min}$. This mixture was allowed to cool to room temperature and then a solution of $\mathrm{CaCl}_{2} \cdot 6 \mathrm{H}_{2} \mathrm{O}(0 \cdot 158 \mathrm{~g}$, $1 \mathrm{mmol})$ in water $(15 \mathrm{~mL})$ was added. Immediately a white precipitate was obtained which was then washed several times with water and dried in a dessicator. Yield: $0.155 \mathrm{~g}\left(70 \%\right.$ based on Ca); M.P. $>250^{\circ} \mathrm{C}$; elemental analysis: (anal. calc. for $\mathrm{C}_{6} \mathrm{H}_{13} \mathrm{O}_{4} \mathrm{PCa}$ ) $\mathrm{C} 32.72, \mathrm{H} 5.97$, found $\mathrm{C} 32 \cdot 14, \mathrm{H} 5 \cdot 97$; IR $\left(\mathrm{KBr}, \mathrm{cm}^{-1}\right)$ : 3593 (w), 3273 (br), 2927 (s), 2851 (w), 1624 (m), 1452 (w), 1275 (w), 1207 (w), 1082 (vs), 1023 (vs), 983 (m), 886 (w), 759 (w), $605(\mathrm{w}), 560(\mathrm{w}), 497(\mathrm{w})$.

\subsection{Synthesis of $\left[\mathrm{Sr}\left(\mathrm{C}_{6} \mathrm{H}_{11} \mathrm{PO}_{3}\right)\left(\mathrm{H}_{2} \mathrm{O}\right)\right]$ (6)}

An amount of $0.147 \mathrm{~g}$ ( $1 \mathrm{mmol}) \mathrm{SrCO}_{3}$ was added portion wise to a solution of $\mathrm{C}_{6} \mathrm{H}_{11} \mathrm{PO}_{3} \mathrm{H}_{2}(0.164 \mathrm{~g}, 1 \mathrm{mmol})$ in water $(25 \mathrm{~mL})$ with continuous stirring. While effervescence was observed, a clear solution was obtained which on heating over a water-bath results in the formation of a white crystalline solid. The product obtained was washed several times with water and then dried in a dessicator. Yield: $0.198 \mathrm{~g}(74 \%$ based on $\mathrm{Sr})$; M.P. $>250^{\circ} \mathrm{C}$; elemental analysis: (anal. calc. for $\mathrm{C}_{6} \mathrm{H}_{13} \mathrm{O}_{4} \mathrm{PSr}$ ) C 26.91, $\mathrm{H} 4 \cdot 89$; found C 28.29, H 4.70; IR ( $\left.\mathrm{KBr}, \mathrm{cm}^{-1}\right): 3445$ (br), 2922 
(s), $2849(\mathrm{~m}), 1448(\mathrm{~m}), 1206(\mathrm{w}), 1128(\mathrm{~s}), 1098(\mathrm{vs})$ 1079 (vs), 1017 (w), 985 (m), 857 (m), 746 (w), 574 (w), $467(\mathrm{w})$.

\subsection{Synthesis of $\mathrm{Ba}\left(\mathrm{C}_{6} \mathrm{H}_{11} \mathrm{PO}_{3}\right)\left(\mathrm{H}_{2} \mathrm{O}\right)$ (7)}

To an aqueous solution of $\mathrm{C}_{6} \mathrm{H}_{11} \mathrm{PO}_{3} \mathrm{H}_{2}(0 \cdot 164 \mathrm{~g}, 1 \mathrm{mmol})$ was added $25 \%$ aqueous solution of $\mathrm{NH}_{3}(0.3 \mathrm{~mL}$, $4 \mathrm{mmol}$ ) and the whole was heated on a water bath for $5 \mathrm{~min}$. The reaction mixture was then allowed to cool to room temperature after which a solution of $\mathrm{BaCl}_{2} \cdot 2 \mathrm{H}_{2} \mathrm{O}$ $(0.244 \mathrm{~g}, 1 \mathrm{mmol})$ in water $(15 \mathrm{~mL})$ was added. Immediately a white crystalline product was formed which was filtered, washed several times with water and then dried in a dessicator. Yield: $0.196 \mathrm{~g}(62 \%$ based on $\mathrm{Ba})$; M.P. $>250^{\circ} \mathrm{C}$; elemental analysis: (anal. calc. for $\mathrm{C}_{6} \mathrm{H}_{13} \mathrm{O}_{4} \mathrm{PBa}$ ), C 22.70, $\mathrm{H} \mathrm{4.12}$; found $\mathrm{C} 22.64, \mathrm{H} 3.98$; IR (KBr, cm ${ }^{-1}$ ): 3349 (br), 2924 (m), 2850 (w), 1666 (br), 1446 (w), 1123 (w), 1048 (vs), 1006 (m), 975 (m), 758 (w), $602(\mathrm{w}), 524(\mathrm{w}), 492(\mathrm{w})$.

\subsection{X-ray structure determination}

Suitable single crystals of compound 14, obtained directly from the reaction mixture, were used for diffraction measurements. The diffraction data were obtained on an Oxford Diffraction XCalibur-S CCD system operating at $150 \mathrm{~K}$. The structure solution and refinement were carried out using the SIR-92 and SHELXL-96 programs, respectively (Altomare et al 1993; Sheldrick 1997). All nonhydrogen atoms were subjected to anisotropic refinement. The hydrogen atoms were placed on calculated positions but were allowed to ride on their parent atoms during subsequent cycles of refinement.

\section{Results and discussion}

\subsection{Synthesis and characterization of} $\mathrm{M}\left(\mathrm{C}_{6} \mathrm{H}_{11} \mathrm{PO}_{3} \mathrm{H}\right)_{2}\left(\mathrm{H}_{2} \mathrm{O}\right)(\mathrm{M}=\mathrm{Ca}$, Sr and $\mathrm{Ba})(\mathbf{1}-\mathbf{3})$

The reaction of appropriate alkaline earth metal salts with cyclohexyl phosphonic acid in aqueous medium, when carried out at ambient temperatures resulted in the formation of $\mathrm{M}\left(\mathrm{C}_{6} \mathrm{H}_{11} \mathrm{PO}_{3} \mathrm{H}\right)_{2}\left(\mathrm{H}_{2} \mathrm{O}\right)(\mathrm{M}=\mathrm{Ca}$, Sr and $\mathrm{Ba})(\mathbf{1}-\mathbf{3})$ in a very high yield (scheme 1). All the three compounds have been characterized using elemental analysis, IR, TGA, and powder X-ray diffraction studies. The molecular structure of compound 2 has been determined using single crystal X-ray diffraction techniques. Structure determination by single crystal X-ray diffraction method has failed in case of compounds $\mathbf{1}$ and $\mathbf{3}$, as very small thin plate crystals suffering from persistent twinning were obtained.

The IR spectra of compounds 1-3 are identical. All of them feature a very broad signal centred on $2300 \mathrm{~cm}^{-1}$ originating from a un-deprotonated $\mathrm{P}-\mathrm{OH}$ group. Strong absorptions observed at 1138 and $1019 \mathrm{~cm}^{-1}$ are attributed to $\mathrm{M}-\mathrm{O}-\mathrm{P}$ and $\mathrm{P}=\mathrm{O}$ stretching vibrations (figure 1). Thermogravimetric analysis of compound 2 (figure 2) shows that the loss of coordinated water molecules occurs at temperature range $99-211^{\circ} \mathrm{C}$ corresponding to the weight decrease of $3.8 \%$ (theoretically $4 \%$ ). Another distinct weight loss of $3.4 \%$ in the temperature range 240 $317^{\circ} \mathrm{C}$ can be attributed to the loss of water molecules formed by the condensation of unreacted $\mathrm{P}-\mathrm{OH}$ groups in compound 2. The dehydrated product remained unchanged till temperature $465^{\circ} \mathrm{C}$ after which the decomposition of the organic fragment corresponding to a weight decrease of $38.5 \%$ occurs in the temperature range $465-$ $556^{\circ} \mathrm{C}$. This weight loss is consistent with the theoretical value of $37.3 \%$ for the conversion of $\operatorname{Sr}\left(\mathrm{C}_{6} \mathrm{H}_{11} \mathrm{PO}_{3} \mathrm{H}\right)_{2}$ to $\mathrm{Sr}\left(\mathrm{PO}_{3}\right)_{2}$. It is noteworthy to mention at this stage that the final material formed when $\operatorname{Sr}\left(\mathrm{C}_{6} \mathrm{H}_{5} \mathrm{PO}_{3} \mathrm{H}\right)_{2}$ was heated up to $570^{\circ} \mathrm{C}$ is also $\mathrm{Sr}\left(\mathrm{PO}_{3}\right)_{2}$ and it is identified by X-ray powder diffraction studies (Mahmoudkhani et al 2002). The TGA profile of compounds $\mathbf{1}$ and $\mathbf{3}$ are identical to that of compound 2 . The powder X-ray diffraction pattern of compounds, 1-3 shows sharp and intense peaks indicating the materials to be highly crystalline, while in figure 3 the powder X-ray diffraction pattern of 2 is depicted. In case of 2 , the most intense peak is observed at $2 \theta=5.28^{\circ}$, which corresponds to an interlayer distance of $16.71 \AA$.

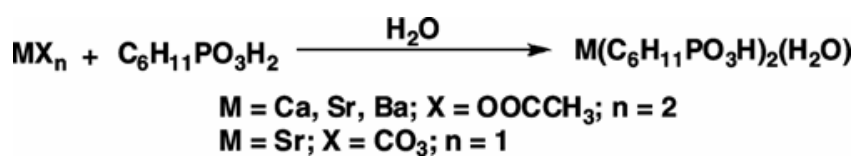

Scheme 1. Synthesis of $\mathrm{M}\left(\mathrm{C}_{6} \mathrm{H}_{11} \mathrm{PO}_{3} \mathrm{H}\right)_{2}\left(\mathrm{H}_{2} \mathrm{O}\right)(\mathrm{M}=\mathrm{Ca}, \mathrm{Sr}$ and $\mathrm{Ba})(\mathbf{1}-\mathbf{3})$.

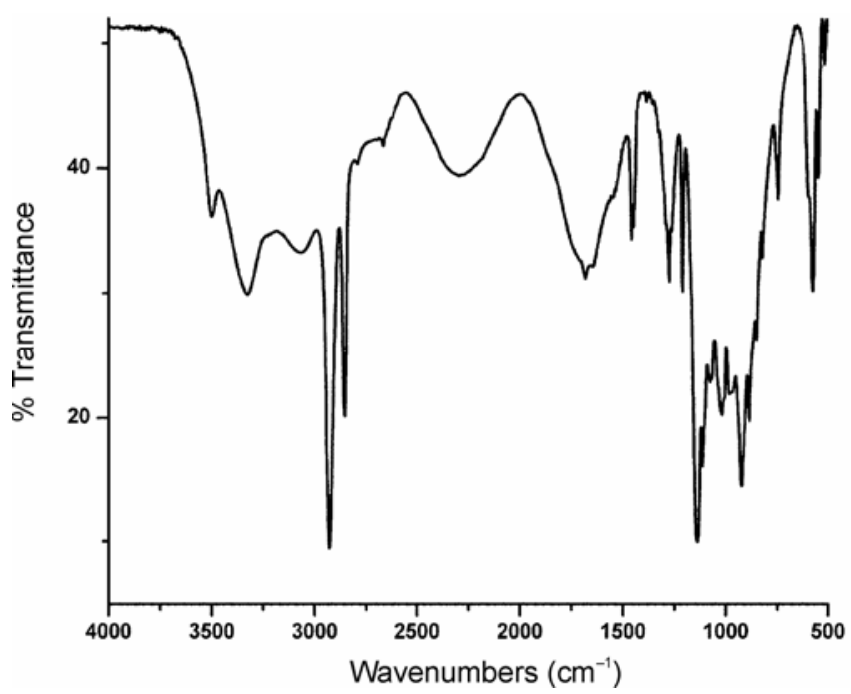

Figure 1. IR spectrum of $\operatorname{Sr}\left(\mathrm{C}_{6} \mathrm{H}_{11} \mathrm{PO}_{3} \mathrm{H}\right)_{2}\left(\mathrm{H}_{2} \mathrm{O}\right)$ (2) (solid, $\mathrm{KBr}$ ). 


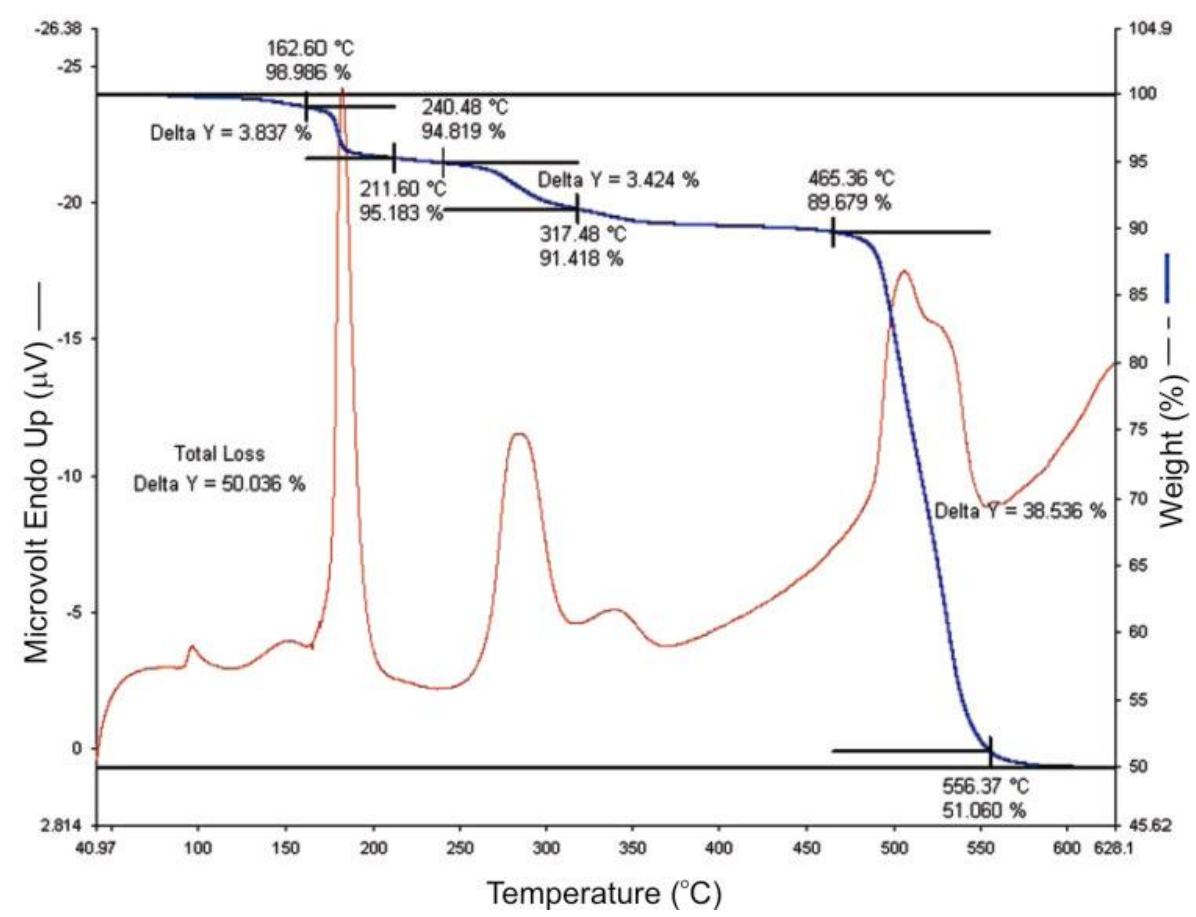

Figure 2. TGA profile of $\operatorname{Sr}\left(\mathrm{C}_{6} \mathrm{H}_{11} \mathrm{PO}_{3} \mathrm{H}\right)_{2}\left(\mathrm{H}_{2} \mathrm{O}\right)(\mathbf{2})\left(\mathrm{N}_{2}\right.$ atm., $\left.10^{\circ} \mathrm{C} / \mathrm{min}\right)$.

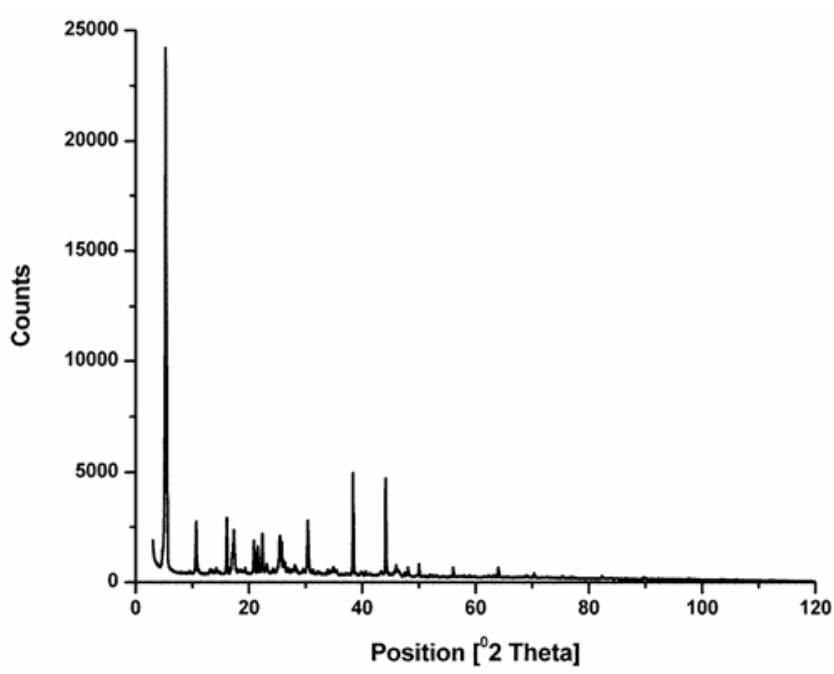

Figure 3. Powder X-ray diffraction pattern of $\operatorname{Sr}\left(\mathrm{C}_{6} \mathrm{H}_{11} \mathrm{PO}_{3} \mathrm{H}\right)_{2}$ $\left(\mathrm{H}_{2} \mathrm{O}\right)(2)$.

The interlayer spacing originates from the attachment of the cyclohexyl groups on both sides of the inorganic backbone.

\subsection{Crystal structure of $\mathrm{Sr}\left(\mathrm{C}_{6} \mathrm{H}_{11} \mathrm{PO}_{3} \mathrm{H}_{2}\left(\mathrm{H}_{2} \mathrm{O}\right)\right.$ (2)}

Colourless, small thin plate like crystals of $\operatorname{Sr}\left(\mathrm{C}_{6} \mathrm{H}_{11} \mathrm{PO}_{3} \mathrm{H}\right)_{2}$ $\left(\mathrm{H}_{2} \mathrm{O}\right)$ (2) suitable for X-ray measurement were obtained from an aqueous solution at ambient temperature. Single crystal X-ray diffraction measurement of the compound,

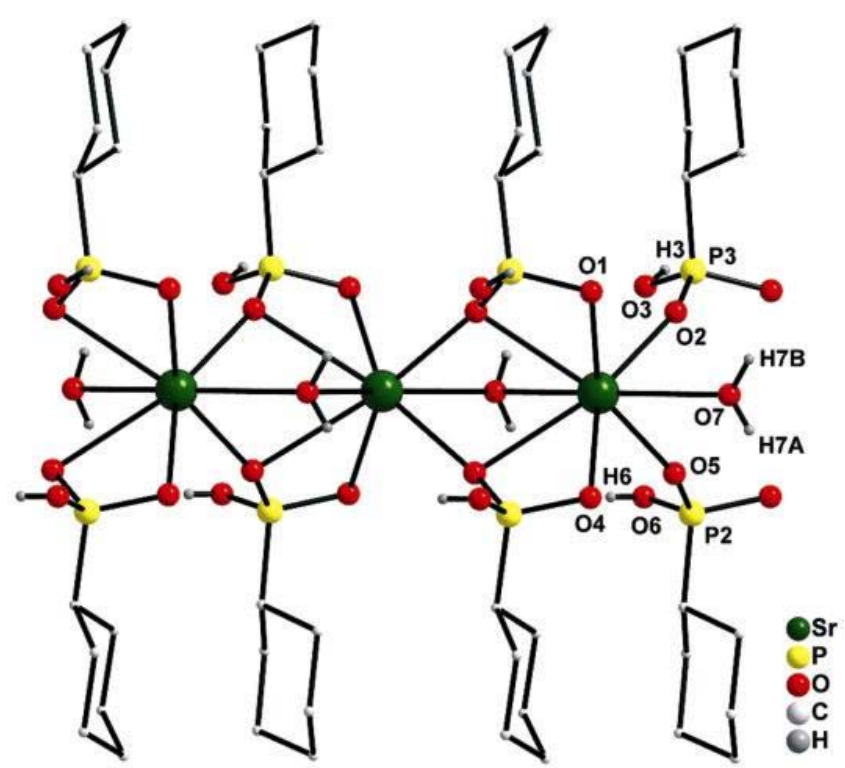

Figure 4. Crystal structure of $\operatorname{Sr}\left(\mathrm{C}_{6} \mathrm{H}_{11} \mathrm{PO}_{3} \mathrm{H}\right)_{2}\left(\mathrm{H}_{2} \mathrm{O}\right)$ (2) Selected bond lengths $(\AA)$ and bond angles $\left({ }^{\circ}\right): \operatorname{Sr}(1)-\mathrm{O}(7)$ 2.632(5); $\mathrm{Sr}(1)-\mathrm{O}(1)$ 2.663(6); $\mathrm{Sr}(1)-\mathrm{O}(4)$ 2.681(5); $\mathrm{Sr}(1)-\mathrm{O}(2)$ $2.842(6) ; \quad \mathrm{Sr}(1)-\mathrm{O}(5) \quad 2.845(6) ; \quad \mathrm{O}(7)-\mathrm{Sr}(1)-\mathrm{O}(1) \quad 78.55(18)$; $\mathrm{O}(7)-\mathrm{Sr}(1)-\mathrm{O}(4)$ 78.16(17); O(1)-Sr(1)-O(4) 92.02(18); O(7)$\mathrm{Sr}(1)-\mathrm{O}(2)$.

$\operatorname{Sr}\left(\mathrm{C}_{6} \mathrm{H}_{11} \mathrm{PO}_{3} \mathrm{H}\right)_{2}\left(\mathrm{H}_{2} \mathrm{O}\right)$ (2), revealed that it crystallizes in a centrosymmetric monoclinic $P 2_{1} / a$ space group and a perspective view of its crystal structure is depicted in figure 4 . The compound exhibits a layered polymeric structure with the cyclohexyl groups pointing out on both 
sides of the inorganic $\mathrm{SrO}_{8}$ framework. Strontium atoms in polymeric 2 are eight coordinated with distorted dodecahedral geometry as oxygen atoms from different phosphonates groups occupy six of the coordinating sites while the other two coordination sites are occupied by two bridging water molecules. The phosphonate group (P3) acts only as a chelating ligand via $\mathrm{O}$, while the other donor oxygen atom, $\mathrm{O} 2$, not only chelates but also bridges the adjacent strontium atoms. There are two different phosphonate ligands related by symmetry (twofold axis) bonded to the same metal atom. Out of the two

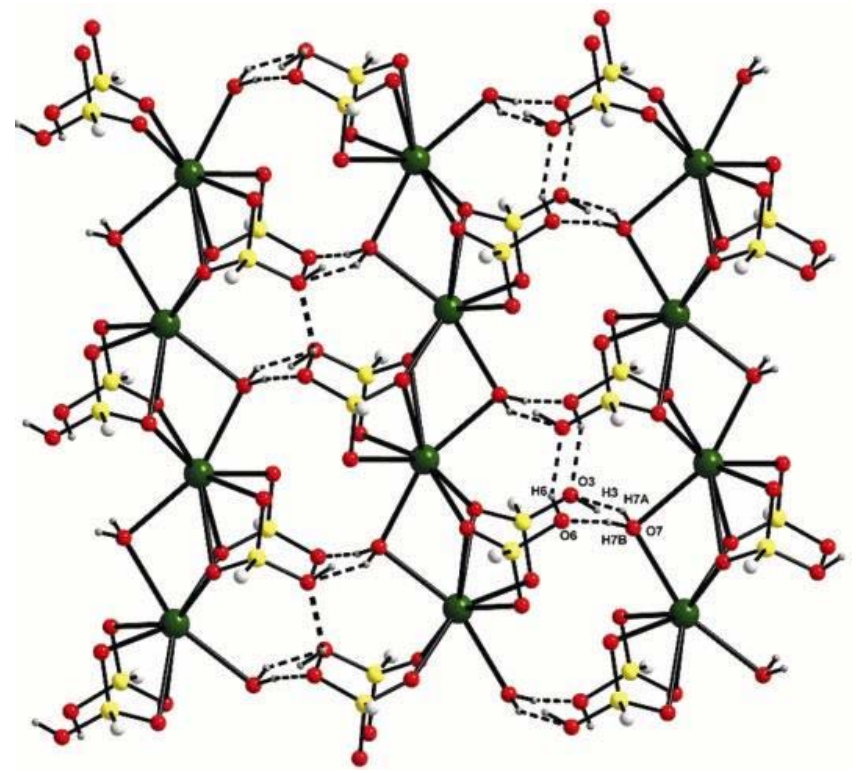

Figure 5. $\mathrm{O}-\mathrm{H} \cdots \mathrm{O}$ hydrogen bonded $2 \mathrm{D}$-sheet formation in $\mathbf{2}$.

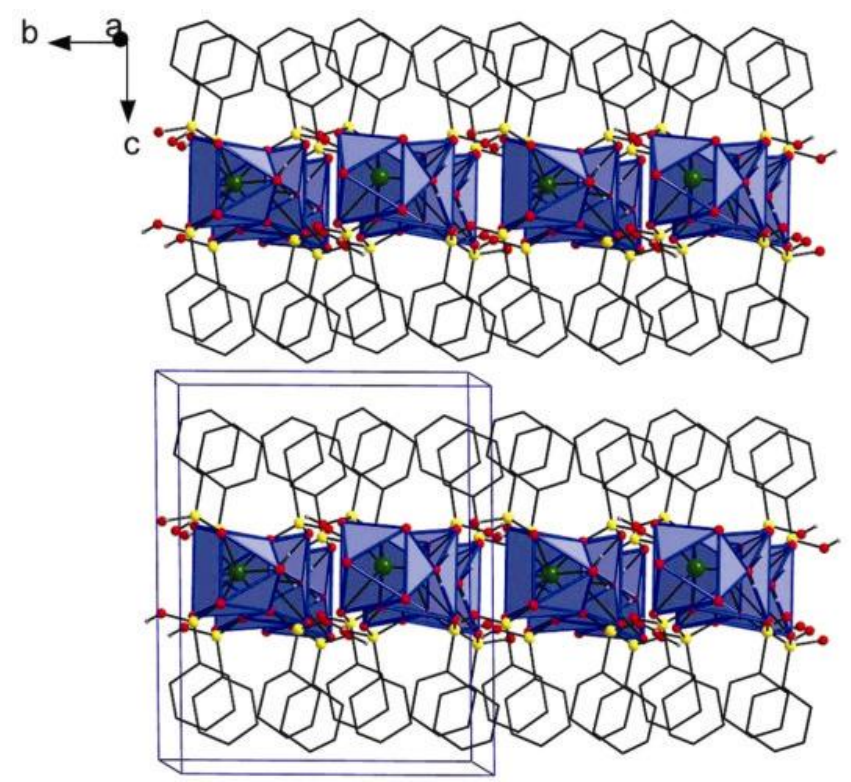

Figure 6. Layered structure in $\operatorname{Sr}\left(\mathrm{C}_{6} \mathrm{H}_{11} \mathrm{PO}_{3} \mathrm{H}\right)_{2}\left(\mathrm{H}_{2} \mathrm{O}\right)($ 2)
$\mathrm{P}-\mathrm{OH}$ groups, one has been deprotonated and is involved in bonding with metal centre while the other $\mathrm{P}-\mathrm{OH}$ group is left un-deprotonated and is involved only in hydrogen bonding. Adjacent strontium atoms in the chain are bridged by two oxygen atoms viz. $\mathrm{O} 2$ and $\mathrm{O} 4$, of the phosphonate ligand, which creates four-membered rings. In addition, strontium atoms in the chain are bridged by $\mathrm{O} 7$ atom of the water molecule. $\mathrm{The} \mathrm{Sr}-\mathrm{O}$ bond distances range between 2.494(5)-2.845(6) $\AA$. Among the six $\mathrm{Sr}-\mathrm{O}(\mathrm{P})$ bond distances those involved in bridging and chelating, $\mathrm{Sr}-\mathrm{O} 2(2 \cdot 842(6) \AA)$ and $\mathrm{Sr}-\mathrm{O} 5$ (2.845(6) $\AA)$ are considerably longer than those involved only in chelating, Sr-O1 and Sr-O4. This kind of long and short bond distances are common in metal phosphonates where the phosphonate ligand is involved both in chelating and bridging. For example, in case of $\mathrm{Ba}\left(\mathrm{C}_{6} \mathrm{H}_{5} \mathrm{PO}_{3} \mathrm{H}\right)_{2}$, the two longest bonds are those involved in chelation to the metal centre (Poojary et al 1996).

Although structure for hydrated alkaline earth metal layered phosphonates were unknown before this, based on ${ }^{31} \mathrm{P}$ NMR data it was suggested that the two water molecules present in $\mathrm{Ca}\left(\mathrm{C}_{6} \mathrm{H}_{5} \mathrm{PO}_{3} \mathrm{H}\right)_{2}\left(\mathrm{H}_{2} \mathrm{O}\right)_{2}$ are mainly involved in hydrogen bonding to the $\mathrm{P}-\mathrm{OH}$ groups (Lima and Airoldi 2002). This is in sharp contrast to our results where the water molecule present in $\operatorname{Sr}\left(\mathrm{C}_{6} \mathrm{H}_{11} \mathrm{PO}_{3} \mathrm{H}\right)_{2}$ $\left(\mathrm{H}_{2} \mathrm{O}\right)(2)$ is coordinated to the metal centre in a bridging mode. To our knowledge compound $\mathbf{2}$ is the first example of structurally characterized alkaline earth metal layered phosphonate of general formula, $\mathrm{M}\left(\mathrm{C}_{6} \mathrm{H}_{5} \mathrm{PO}_{3} \mathrm{H}\right)_{2}\left(\mathrm{H}_{2} \mathrm{O}\right)$, where the central metal exhibits an octa-coordination. Earlier examples of structurally characterized alkaline earth metal phosphonates contain either a eight coordinated e.g. $\mathrm{Ca}\left(\mathrm{C}_{6} \mathrm{H}_{5} \mathrm{PO}_{3} \mathrm{H}\right)_{2}$ (Mahmoudkhani and Langar 2001), $\operatorname{Sr}\left(\mathrm{C}_{6} \mathrm{H}_{5} \mathrm{PO}_{3} \mathrm{H}\right)_{2}$ (Mahmoudkhani et al 2002), $\mathrm{Ba}\left(\mathrm{C}_{6} \mathrm{H}_{5} \mathrm{PO}_{3} \mathrm{H}\right)_{2}$ (Poojary et al 1996) or seven coordinated metal centre (e.g. $\mathrm{Ca}\left(\mathrm{CH}_{3} \mathrm{PO}_{3}\right)\left(\mathrm{H}_{2} \mathrm{O}\right)$ (Cao et al 1990).

The free, un-deprotonated $\mathrm{P}-\mathrm{OH}$ groups in $\mathbf{2}$ are involved in intermolecular hydrogen bonding with the bridged water molecules to form a twelve-membered ring $\mathrm{O}(6) \cdots \mathrm{O}(3) 2 \cdot 477(9) \AA, \mathrm{O}(6)-\mathrm{H}(6) \cdots \mathrm{O}(3) 149(18)^{\circ}$, $\mathrm{O}(7) \cdots \mathrm{O}(3) \quad 2.696(8), \quad \mathrm{O}(7)-\mathrm{H}(7 \mathrm{~A}) \cdots \mathrm{O}(3) \quad 152(9)^{\circ}$, $\mathrm{O}(7) \cdots \mathrm{O}(6) 2.686(9), \mathrm{O}(7)-\mathrm{H}(7 \mathrm{~B}) \cdots \mathrm{O}(6) 172(12)^{\circ}$. There are two different free $\mathrm{P}-\mathrm{OH}$ moieties present in compound 2 , one of which forms hydrogen bond involving both the oxygen and hydrogen atoms while the other P$\mathrm{OH}$ moiety forms hydrogen bond involving only the oxygen atom. So the polymeric chains are interconnected via $\mathrm{O}-\mathrm{H} \cdots \mathrm{O}$ hydrogen bonds, leading to the formation of a

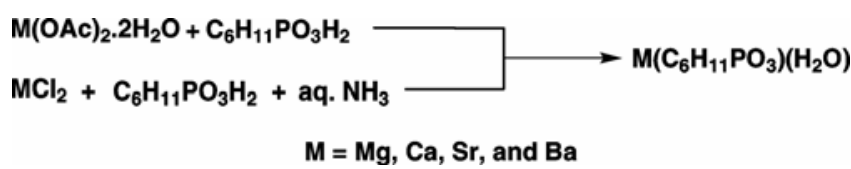

Scheme 2. Synthesis of $\mathrm{M}\left(\mathrm{C}_{6} \mathrm{H}_{11} \mathrm{PO}_{3}\right)\left(\mathrm{H}_{2} \mathrm{O}\right)(\mathrm{M}=\mathrm{Mg}, \mathrm{Ca}, \mathrm{Sr}$ and $\mathrm{Ba}$ ) (4-7). 
Table 1. Crystal data and structure refinement for compound 2.

\begin{tabular}{lll}
\hline Identification code & newrm030 & \\
Empirical formula & $\mathrm{C}_{12} \mathrm{H}_{26} \mathrm{O}_{7} \mathrm{P}_{2} \mathrm{Sr}$ & \\
Formula weight & $131 \cdot 89$ & \\
Temperature & $150(2) \mathrm{K}$ \\
Wavelength & Monoclinic & \\
Crystal system & $P 2{ }_{1} / a$ & $\alpha=90^{\circ}$ \\
Space group & $a=7 \cdot 9631(18) \AA$ & $\beta=100 \cdot 70(2)^{\circ}$ \\
Unit cell dimensions & $b=13 \cdot 405(3) \AA$ & $\gamma=90^{\circ}$ \\
& $c=16 \cdot 662(6) \AA$ & \\
& $1747 \cdot 6(8) \AA^{3}$ & \\
Volume & 4 & \\
$Z$ & $1 \cdot 642 \mathrm{Mg} / \mathrm{m}^{3}$ & \\
Density (calculated) & $3 \cdot 296 \mathrm{~mm}$ & \\
Absorption coefficient & 888 & \\
$F(000)$ & $0 \cdot 21 \times 0 \cdot 11 \times 0 \cdot 08 \mathrm{~mm}^{3}$ & \\
Crystal size & $3 \cdot 04$ to $24 \cdot 99^{\circ}$. & \\
Theta range for data collection & $-9<=h<=9,-15<=k<=15,-16<=1<=19$ \\
Index ranges & 15106 & \\
Reflections collected & $3011[R(\mathrm{int})=0 \cdot 0498]$ & \\
Independent reflections & $97 \cdot 5 \%$ & \\
Completeness to theta $=24 \cdot 99^{\circ}$ & $0 \cdot 7784$ and $0 \cdot 5444$ & \\
Max. and min. transmission & Full-matrix least-squares on $F^{2}$ \\
Refinement method & $3011 / 0 / 211$ & \\
Data/restraints/parameters & $1 \cdot 089$ & \\
Goodness-of-fit on $F^{2}$ & $R 1=0 \cdot 0814, w R 2=0 \cdot 2047$ & \\
Final $R$ indices $[I>2$ sigma(I) $]$ & $R 1=0 \cdot 1020, w R 2=0 \cdot 2190$ & \\
$R$ indices (all data) & $4 \cdot 931$ and $-0 \cdot 953 \mathrm{e} . \AA^{-3}$ & \\
Largest diff. peak and hole & & \\
\hline
\end{tabular}
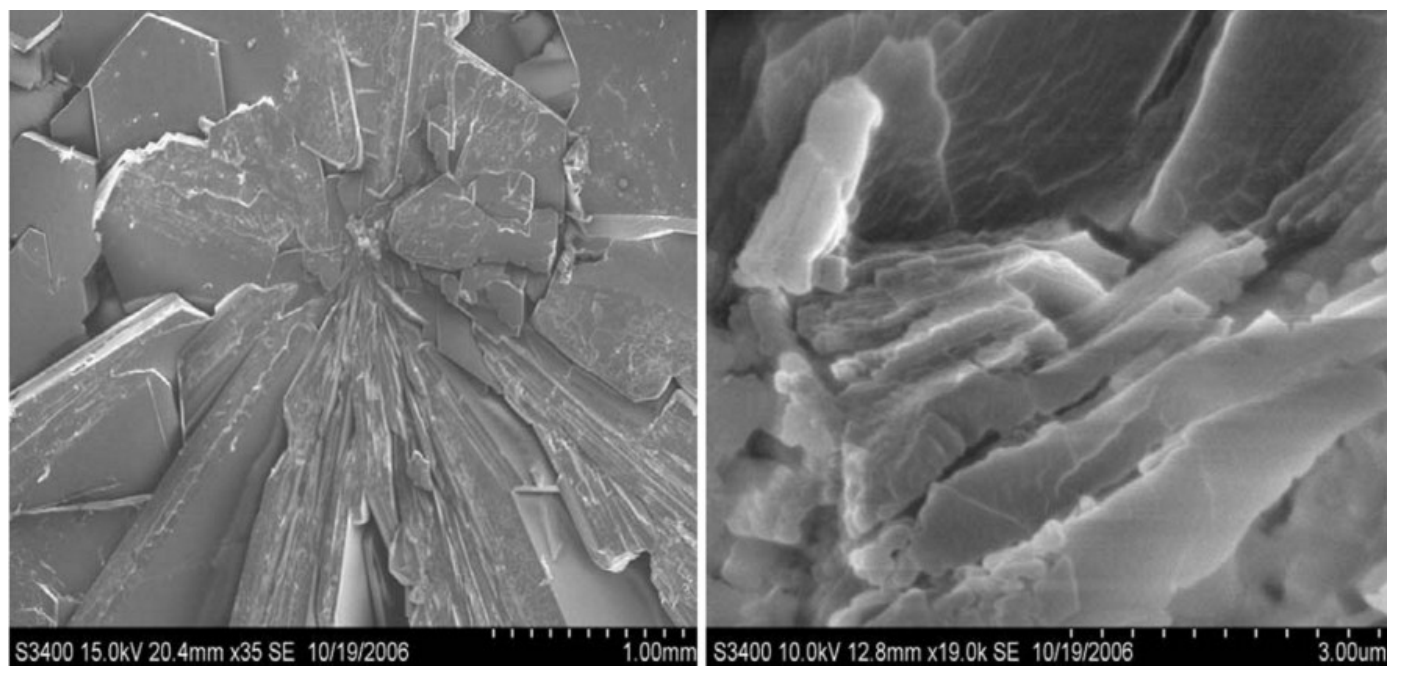

Figure 7. SEM images of crystals of 2

2D sheet structure as shown in figure 5. The arrangement of the cyclohexyl groups in the interlayer space down $b$ axis is shown in figure 6 . It is evident from this picture that $\mathrm{Sr}\left(\mathrm{C}_{6} \mathrm{H}_{11} \mathrm{PO}_{3} \mathrm{H}\right)_{2}\left(\mathrm{H}_{2} \mathrm{O}\right)$ has a layered structure with two-dimensional sheets of neutral $\operatorname{Sr}\left(\mathrm{C}_{6} \mathrm{H}_{11} \mathrm{PO}_{3} \mathrm{H}\right)_{2}\left(\mathrm{H}_{2} \mathrm{O}\right)$ stacked along the crystallographic $a$ axis. The layered structure in compounds 13-15 is translated in their physical appearance and in all the cases the crystals are formed as thin flakes stacked one over the other. Figure 7 depicts a scanning electron micrograph showing the presence of layered morphology in the crystalline state.

\subsection{Synthesis and characterization of $M\left(\mathrm{C}_{6} \mathrm{H}_{11} \mathrm{PO}_{3}\right)\left(\mathrm{H}_{2} \mathrm{O}\right)(\mathrm{M}=\mathrm{Mg}, \mathrm{Ca}, \mathrm{Sr}$, and $\mathrm{Ba})(4-7)$}

In case of compounds 1-3, only one $\mathrm{P}-\mathrm{OH}$ group of cyclohexyl phosphonic acid has reacted while the other $\mathrm{P}-\mathrm{OH}$ group is free. By slightly modifying the reaction 


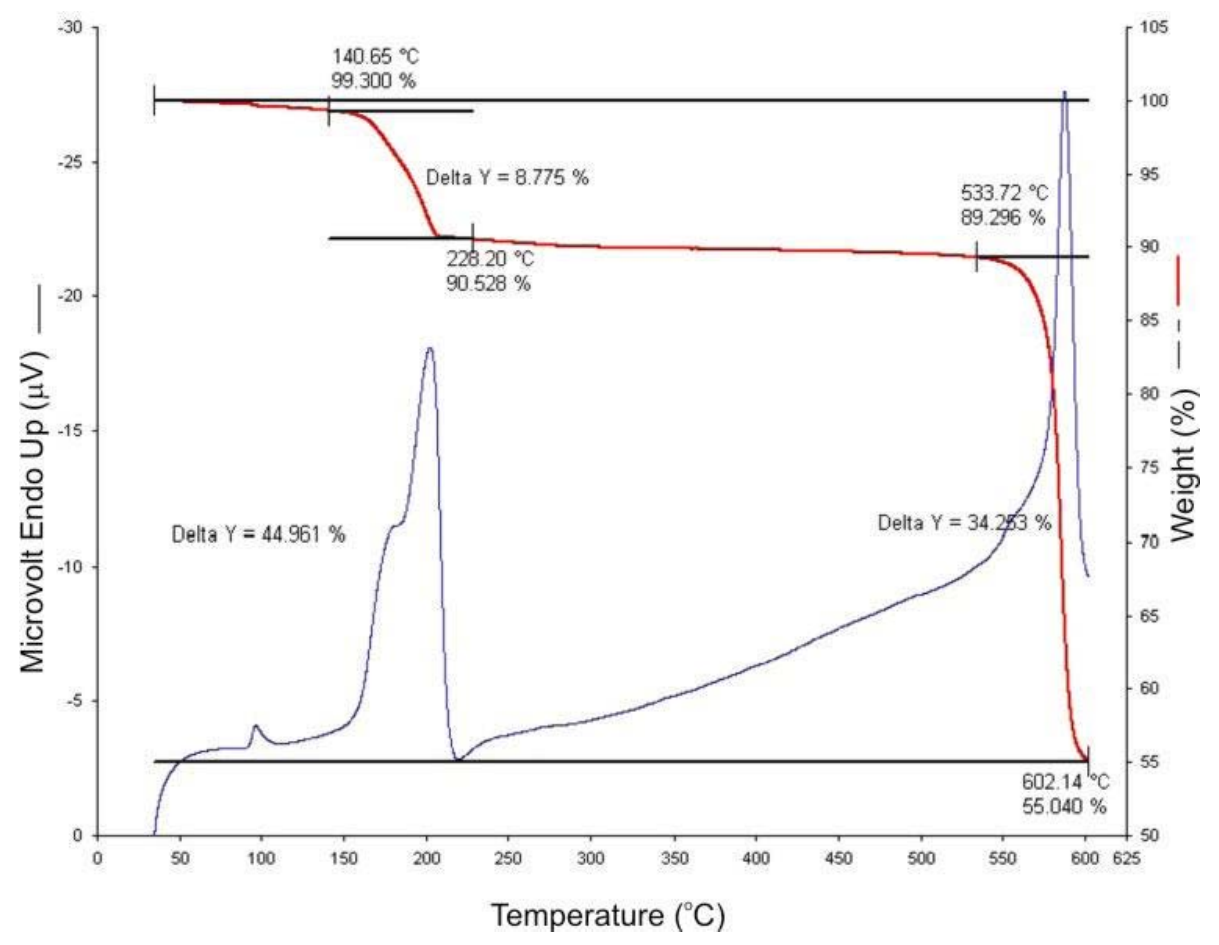

Figure 8. TGA profile of $\mathrm{Ca}\left(\mathrm{C}_{6} \mathrm{H}_{11} \mathrm{PO}_{3}\right)\left(\mathrm{H}_{2} \mathrm{O}\right)(\mathbf{5})\left(\mathrm{N}_{2}\right.$ atm., $\left.10^{\circ} \mathrm{C} / \mathrm{min}\right)$.

conditions, it has been possible to de-protonate both the $\mathrm{P}-\mathrm{OH}$ groups and obtain a series of compounds with general formula, $\mathrm{M}\left(\mathrm{C}_{6} \mathrm{H}_{11} \mathrm{PO}_{3}\right)\left(\mathrm{H}_{2} \mathrm{O}\right)(\mathrm{M}=\mathrm{Mg}, \mathrm{Ca}, \mathrm{Sr}$, and Ba) (4-7) (scheme 2). Unlike the case of $\mathrm{Mg}$ and $\mathrm{Sr}$, where slight increase in the reaction temperature led to the formation of $\mathrm{M}\left(\mathrm{C}_{6} \mathrm{H}_{11} \mathrm{PO}_{3}\right)\left(\mathrm{H}_{2} \mathrm{O}\right)(\mathrm{M}=\mathrm{Mg}$ and $\mathrm{Sr})(4$ and 6), the corresponding product for $\mathrm{Ca}$ and $\mathrm{Ba}$ could not be obtained, even at an elevated temperature as they yielded the earlier described products, $\mathrm{M}\left(\mathrm{C}_{6} \mathrm{H}_{11} \mathrm{PO}_{3} \mathrm{H}\right)_{2}$ $\left(\mathrm{H}_{2} \mathrm{O}\right)(\mathrm{M}=\mathrm{Ca}$ and $\mathrm{Ba})(\mathbf{1}$ and $\mathbf{3})$. Instead, when we tried to increase the $\mathrm{pH}$ of the reaction system by the addition of excess of aqueous ammonia, $\mathrm{M}\left(\mathrm{C}_{6} \mathrm{H}_{11} \mathrm{PO}_{3}\right)\left(\mathrm{H}_{2} \mathrm{O}\right)$ $(\mathrm{M}=\mathrm{Ca}$ and $\mathrm{Ba})$ (5 and 7) could be isolated in a very high yield (scheme 2). Thus first an aqueous solution of cyclohexyl phosphonic acid was allowed to react with excess of ammonia and then addition of one equivalent of $\mathrm{CaCl}_{2}$ to the above solution resulted in the immediate formation of $\mathrm{M}\left(\mathrm{C}_{6} \mathrm{H}_{11} \mathrm{PO}_{3}\right)\left(\mathrm{H}_{2} \mathrm{O}\right)(\mathrm{M}=\mathrm{Ca}$ and $\mathrm{Ba})(5$ and 7 ), as a white crystalline solid. Compounds 5-7 have been characterized using elemental analysis, IR, TGA and powder X-ray diffraction techniques.

IR spectra of compounds 4-7 are identical. As no broad signal in the region $2300-2400 \mathrm{~cm}^{-1}$ has been observed, the presence of any free, un-deprotonated $\mathrm{P}-\mathrm{OH}$ groups can be ruled out. The $\mathrm{P}=\mathrm{O}$ and $\mathrm{M}-\mathrm{O}-\mathrm{P}$ stretching vibrations are observed at 1082 and $1023 \mathrm{~cm}^{-1}$. Thermogravimetric analysis of compound 5 (figure 8) shows the loss of adsorbed water molecule around $100^{\circ} \mathrm{C}$ while the weight decrease of $8.8 \%$ in temperature range $141-228^{\circ} \mathrm{C}$ accounts for the loss of coordinated water molecule (theoretically $8 \cdot 17 \%$ ). The dehydrated sample remains unchanged until $534^{\circ} \mathrm{C}$ after which the decomposition of the organic fragment occurs. The powder X-ray diffraction pattern of $\mathrm{Ca}\left(\mathrm{C}_{6} \mathrm{H}_{11} \mathrm{PO}_{3}\right)\left(\mathrm{H}_{2} \mathrm{O}\right)$ (5) shows sharp and intense peaks indicating the material to be highly crystalline. The most intense peak is observed at $2 \theta=5.65^{\circ}$, which corresponds to an interlayer distance of $15.62 \AA$.

\section{Conclusions}

To summarize we have synthesized two homologous series of alkaline earth metal cyclohexyl phosphonates, $\mathrm{M}\left(\mathrm{C}_{6} \mathrm{H}_{11} \mathrm{PO}_{3} \mathrm{H}\right)_{2}\left(\mathrm{H}_{2} \mathrm{O}\right)(\mathrm{M}=\mathrm{Ca}, \mathrm{Sr}$ and $\mathrm{Ba})(\mathbf{1}-\mathbf{3})$ and $\mathrm{M}\left(\mathrm{C}_{6} \mathrm{H}_{11} \mathrm{PO}_{3}\right)\left(\mathrm{H}_{2} \mathrm{O}\right)(\mathrm{M}=\mathrm{Mg}, \mathrm{Ca}, \mathrm{Sr}$, and $\mathrm{Ba})(4-7)$, under mild reaction conditions. All these compounds were characterized using various analytical and spectroscopic techniques, while single crystal X-ray studies carried out for 2 verify its layered structure with hydrophobic cyclohexyl groups pointing out of the inorganic core. The one dimensional chains in $\mathbf{2}$ form intermolecular hydrogen bonding to result in a $2 \mathrm{D}$ sheet-like structure.

\section{Acknowledgements}

This work was supported by DST, New Delhi and CSIR, New Delhi. (NG) thanks CSIR, New Delhi, for financial assistantship in the form of a senior research fellowship. We thank the DST funded National Single Crystal Di- 
ffraction Facility at IIT Bombay for diffraction data. We also thank SAIF, IIT Bombay for the analytic and spectroscopic data.

\section{References}

Alberti G 1978 Acc. Chem. Res. 11163

Alberti G, Allulli S, Constantino U and Tomassini N $1978 \mathrm{~J}$. Inorg. Nucl. Chem. $\mathbf{4 0} 1113$

Altomare A, Cascarano G, Giacovazzo C and Gualardi Z 1993 J. Appl. Crystallogr. 26343

Cao G, Lee H, Lynch V M and Mallouk T E 1988a Inorg. Chem. 272781

Cao G, Lee H, Lynch V M and Mallouk T E 1988b Solid State Ionics 2663

Cao G, Lynch V M, Swinnea J S and Mallouk T E 1990 Inorg. Chem. 292112

Cao G, Hong H G and Mallouk T 1992 Acc. Chem. Res. 25420

Clayton J O and Jensen W L 1948 J. Am. Chem. Soc. 783880

Clearfield A 1998 Progr. Inorg. Chem. 4747
Lee H, Kepley L J, Hong H G and Mallouk T E 1988a J. Am. Chem. Soc. 110618

Lee H, Kepley L J, Hong H G, Akhter S and Mallouk T E 1988b J. Phys. Chem. 92597

Lima C B A and Airoldi C 2002 Solid State Sci. 41321

Mahmoudkhani A H and Langer V 2001 Solid State Sci. 3 519

Mahmoudkhani A H, Langer V and Smrcok L 2002 Solid State Sci. 4873

Murugavel R, Davis P and Walawalkar M G 2005 Z. Anorg. Allg. Chem. 6312806

Poojary D M, Zhang B, Cabeza A, Aranda M A G, Bruque S and Clearfield A 1996 J. Mater. Chem. 6639

Sheldrick GM 1997 SHELXL-97 (Germany: University of Göttingen)

Svoboda J, Zima V, Benes L, Klara M and Vlcek M 2005 Inorg. Chem. 449968

Ungashe S B, Wilson W L, Katz H E, Scheller T and Putvinski M 1992 J. Am. Chem. Soc. 1148717

Wan B -Z, Anthony R G, Peng G -Z and Clearfield A 1994 J. Catal. 19101 